Original Article

\title{
INVESTIGATION OF ANTHELMINTIC EFFECT OF NEOLAMARCKIA CADAMBA FRUIT EXTRACTS IN ASCARIASIS
}

\author{
KULDEEP KAUR, AJEET PAL SINGH, AMAR PAL SINGH
}

St. Soldier Institute of Pharmacy, Lidhran Campus, Behind NIT (R. E. C), Jalandhar-Amritsar by pass NH-1 Jalandhar 144011, Punjab, India Email: kuldeepkaur9757@gmail.com

Received: 08 May 2021, Revised and Accepted: 07 Jul 2021

\begin{abstract}
Objective: Investigation of Anthelmintic effect of Neolamarckia Cadamba fruit extracts (Ethanol, Aquaous, Phenyl ether, Chloroform) in Ascariasis.

Methods: The experiment was conducted on an adult Indian earthworm, Eiseniafoetida, owing of its morphological and physiological similarities to the human intestine roundworm parasite. Six sets of six earthworms were discharged sequentially into different extracts of $\mathrm{N}$. cadamba fruits at dose levels of 5,10,15,20, and $25 \mathrm{mg} / \mathrm{ml}$, respectively, and $25 \mathrm{mg} / \mathrm{ml}$ of albendazole solutions. Albendazole was employed as the standard reference medication.

Results: The results showed that Ethanolic extract has the greatest degree of activity. When compared to any other extract or conventional medicine, it produces a paralytic effect sooner and has a shorter time to death (Albendazole). An ethanol extract included alkaloid, saponin, tannins, flavonoids, proteins, and amino acids. As a result, it is possible to infer that the ethenolic fruit extract of Neolomarckia Cadamba showed much more anthelmintic activity against Indian earthworms than the usual treatment (Albendazole).
\end{abstract}

Conclusion: The solvents Ethanol, Chloroform, Phenyl Ether, and Aquaous were used to extract the Neolamarckia Cadamba. The results showed that Ethanolic extract has the greatest degree of activity. When compared to any other extract or conventional medicine, it produces a paralytic effect sooner and has a shorter time to death (Albendazole).

Keywords: Helminthiasis, Neolamarckia cadamba, Anthelmintic activity, Extracts, Ascariasis

(C) 2021 The Authors. Published by Innovare Academic Sciences Pvt Ltd. This is an open-access article under the CC BY license (https://creativecommons.org/licenses/by/4.0/) DOI: https://dx.doi.org/10.22159/ijcpr.2021v13i5.1897 Journal homepage: https://innovareacademics.in/journals/index.php/ijcpr

\section{INTRODUCTION}

Worm-borne illness, parasitic diseases caused by intestinal helminthes and protozoan parasites are among the most prevalent infections in developing countries. In developed countries, protozoan parasites are more often than helminths to cause gastrointestinal disease. Infectious intestinal parasites are a significant cause of disease and mortality in endemic regions [1]. Helminthiasis is a widespread disease caused by Platyhelminthes (flatworms) and Nematodes species (roundworms). The disease is transmitted through the fecal-oral route, active skin penetration by soil larvae or vector arthropods. Helminthiasis is common in poorer countries and places with poor sanitation, but it also develops in areas where it is not endemic as a result of immigration and travel. According to the World Health Organization, about 2 billion people worldwide are afflicted with helminthic infections. These infections are linked with a high morbidity and mortality rate, including anaemia from iron deficiency, convulsions, portal hypertension, and chronic diarrhoea. Because of their frequent interaction with dirt and the potential of putting their fingers in their mouths, children are at a significant risk of illness. Furthermore, children are vulnerable to serious helminthic infection effects such as malnutrition, anaemia, intestinal obstruction, and learning disabilities [2]. Because the clinical symptoms of helminthic sickness and its repercussions are often ambiguous, familiarity with common imaging results may help in the identification and treatment of these illnesses. Worm infections (also known as helminth infections) are one of the most common diseases among children living in extreme poverty in Asia, Africa, and Latin America. Furthermore, an alarmingly high proportion of children in the United States and Europe are worminfected [3]. Enterobius vermicular infection of the intestine is a common parasitic infection that is seldom symptomatic. It is unusual to find it outside of the gastrointestinal system or in the wall. We discovered five cases when the worm was identified outside of the intestine's lumen.

\section{Ascariasis}

In the stomach, parasites of the genus Ascaris live. Ascaris eggs are spread via infected people's faeces (poop). Worm eggs are deposited on the soil when an infected person defecates outdoors (for example, near bushes, in a garden, or in a field), or when an infected person's faeces is used as fertiliser. The worm eggs may then mature into a parasite that may infect others. Ascariasis is caused by eating worm eggs. This may happen if you put sick hands or fingers in your mouth or if you consume vegetables or fruits that haven't been properly peeled, washed, or cooked [4-6].

\section{Symptoms}

The vast majority of people with ascariasis do not have any symptoms. Infestations of moderate to severe severity cause a range of symptoms, depending on the region of the body affected [7].

\section{In the lungs}

After swallowing the microscopic ascariasis eggs, they hatch in the small intestine and travel into the lungs through the bloodstream or lymphatic system. At this stage, the person may exhibit signs and symptoms similar to those seen in asthma or pneumonia, such as: Cough that does not go away, Breathlessness, and Wheezing [7].

\section{In the intestines}

Adult worms grow from larvae in the small intestine, and they typically live in the intestines until they die. The intestinal infection in instances of moderate or severe ascariasis may cause the following symptoms are abdominal pain that is not definite, Nausea and vomiting, Diarrhea or bloody faeces, the abdominal pain is excruciating. Fatigue, Obesity or malnourishment, A worm discovered in vomit or faeces [7].

\section{Causes of an ascariasis infection}

It may get ascariasis if it eats the eggs of the roundworm Ascariasis lumbricoides accidentally. The eggs may be found in soil that has been contaminated with human faeces or in uncooked food that has been infected with roundworm eggs. According to the World Health Organization, children often get ill after putting their hands in their mouths after playing in contaminated soil. Additionally, ascariasis may be passed from person to person [8]. 


\section{Worldwide effect of ascariasis}

The largest of the intestinal nematodes (roundworms) that parasitize the human gastrointestinal tract is Ascaris lumbricoides. It is the cause of ascariasis, a neglected tropical disease (NTD) that is one of the most common helminthic human illnesses in the world, affecting between 800 million and 1.2 billion people. Every year, about 60,000 people are killed by it. However, over $85 \%$ of infections are asymptomatic, especially in individuals infected with a small number of worms. As a result, many individuals with intestinal ascariasis go undiagnosed for years until they develop symptoms and seek medical attention, the macroscopic adult worms are passed in the stool, or the adult worms are discovered inadvertently during routine endoscopic exams. We provide an interesting case of an elderly Bangladeshi man who was identified with intestinal ascariasis during a screening colonoscopy despite having seemingly innocuous symptoms of occasional mild stomach discomfort and no recent travel history [9].

\section{Transmission}

Transmission occurs mostly via the ingestion of contaminated water or food (particularly raw vegetables or fruit) and, on rare instances, by the inhalation of contaminated dust. Children who play in contaminated soil run the danger of acquiring the parasite via their hands. On rare occasions, larvae have been seen to move transplacentally. As a consequence of similar transmission risk factors, confection with other parasite diseases happens with some regularity [10].

\section{Life cycle}

Adult worms reside in the small intestine's jejunum or ileum. They survive for 10 to $2 \mathrm{y}$ and ultimately pass via the faeces. When both male and female worms are present in the stomach, each female worm produces about 200,000 fertilized eggs each day. Asexual illnesses produce sterile eggs, which do not develop into infectious worms. Female worms do not produce eggs. The oval ova is defined by a thick shell and a mamillated outer covering. In two to four weeks, embryos develop into infective second-stage larvae in the environment (depending upon environmental conditions). When the eggs are consumed, larvae penetrate the intestinal wall and migrate hematogenously or through lymphatics to the heart and lungs. In addition to the lungs, larvae may migrate to the kidneys or the brain. Larvae enter the lungs four days after digesting eggs. The larvae spend approximately $10 \mathrm{~d}$ developing in the alveoli of the lungs before moving up the bronchi and trachea and being swallowed. Adult worms emerge from the stomach. Worms may be found from the oesophagus to the rectum, with the majority being found in the jejunum. After two to three months, gravid females begin to produce eggs, completing the cycle. When infected, the number of adult worms per infected person is determined by the length of time exposed to infectious eggs. In extremely endemic areas, there have been reports of children carrying more than 2,000 worms. As worm burden increases, the number of eggs produced per female worm falls. Every day, 9 10(14) eggs contaminate the earth's soil [10].

\section{Ascaris lumbricoides}

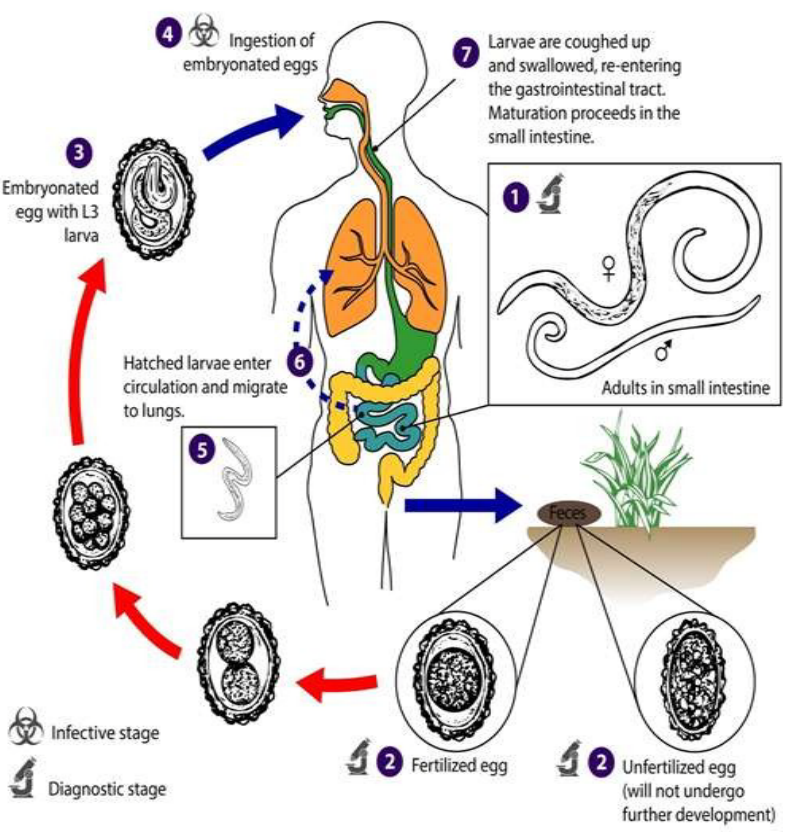

Fig. 1: Life cycle of ascaris lumbricoids

\section{MATERIALS AND METHODS}

\section{Plant}

Procurement and authentication: The extract of Neolamarckaia cadamba was collected from Shreedha phyto extracts, manufacturer of herbal Extracts and Nutraceuticals, Jaipur. The plant was identified and authenticated by Dr. (Mrs) Sunita Garg Head, Raw Materials Herbarium and Museum, Delhi (RHMD), National Institute of Science Communication And Information Resources (CSIRNISCAIR), New Delhi-110022.

\section{Anthelmintic activity}

Earthworms of species Eiseniafoetida were used. All the experiments were carried out in Indian earthworms (Eiseniafoetida) collected from Krishivigyan Kendra kapurthala, Punjab, India. The earthworms were selected because of its anatomical and physiological resemblance with the intestinal roundworm parasite Ascaris lumbricoids, of human beings [12]. Because of easy availability, earthworms have been used widely for the initial evaluation of anthelmintic compounds in vitro.

\section{Chemical and reagents}

All the chemicals, including Albendazole and reagents, were procured from local suppliers and were of analytical grade.

\section{Evaluation of anthelmintic activity}

The earthworms were divided into 6 groups and each group comprised of 6 worms. The allocation of earthworms to various 
groups was done as given in table-for plant extract. Statistical analysis. The data of anthelmintic activity was expressed as mean \pm SEM of six earthworms in each group. The statistical analysis was carried out using one-way ANOVA followed by Dunnet $\mathrm{t}$-test. The difference in values at $\mathrm{P}<0.05$ was considered as statistically significant. The analysis of variance (ANOVA) was performed using Graph pad Prism 5 (Version 5.03) software to determine the mean and standard error of paralysis and, m, death time of the earthworms [12].

\section{Procedure}

The experiment was carried out on an adult Indian earthworm, Eiseniafoetida since it is morphologically and physiologically similar to the human intestinal roundworm infection. Adult earthworms were collected from damp soil and washed with normal saline to remove any faeces. Earthworms $3-5 \mathrm{~cm}$ long and $0.1-0.2 \mathrm{~cm}$ broad were used in all studies. Earthworms were dropped into various extracts of $\mathrm{N}$. cadamba fruits at dosages of $5,10,15,20,25$, and 25 $\mathrm{mg} / \mathrm{ml}$, as well as albendazole solutions at $25 \mathrm{mg} / \mathrm{ml}$. The reference drug was albendazole. Individual worms' paralysis and death were timed. Except when the worms were forcefully shaken, paralysis was defined as no movement. The worms perished when they stopped moving $[13,14]$.

Firstly took six groups of six earthworms were released into the extract of Phenyl ether one by one with dose 5, 10,15,20,25 $\mathrm{mg} / \mathrm{ml}$ each and in albendazole of dose $25 \mathrm{mg} / \mathrm{ml}$

- Secondly took six groups of six earthworms were released into the extract of Chloroform one by one with dose 5, 10,15,20,25 $\mathrm{mg} / \mathrm{ml}$ each and in albendazole of dose $25 \mathrm{mg} / \mathrm{ml}$.

- Then took six groups of six earthworms were released into the extract of Ethanol one by one with doses 5, 10,15,20,25 mg/ml each and in albendazole of dose $25 \mathrm{mg} / \mathrm{ml}$.

- At the end took six groups of six earthworms were released into the extract of aqueous one by one with dose $5,10,15,20,25 \mathrm{mg} / \mathrm{ml}$ each and in albendazole of dose $25 \mathrm{mg} / \mathrm{ml}$.

\section{Phytochemical studies of neolamarckaia cadamba}

It was extracted for $24 \mathrm{~h}$ using petroleum ether $\left(60-80{ }^{\circ} \mathrm{C}\right)$, chloroform, ethanol, and water using Soxhlet apparatus. Following extraction, the liquid extracts were condensed at a low pressure using a rotary evaporator to yield dry residues. The extracts were submitted to a preliminary phytochemical screening using established methods to assess their phytoconstituent makeup [15].

Preliminary phytochemical screening of various extracts (table 4 and 5) revealed the presence of alkaloids (in chloroform and methanol extracts), carbohydrates, proteins, gum (in aqueous extract), steroids (in petroleum ether, chloroform, and ethanol extracts), triterpenoids (in petroleum ether and chloroform extracts), saponin (in chloroform, ethanol, and aqueous extracts), and flavonoids [16].

\section{RESULTS AND DISCUSSION}

Evaluation of phenyl etherneolamarckia cadambafruitextract effects in earthworm different doses were shown in table 1 and fig. 2 .

- In Phenyl Ether Neolamarckia Cadamba extract, test group one with Dose $5 \mathrm{mg} / \mathrm{ml}$ taken $20.34 \pm 1.95 \mathrm{sec}$ to paralysis the earthworm and $21 \pm 1.99 \mathrm{~min}$ for Death.

- Test group two with Dose $10 \mathrm{mg} / \mathrm{ml}$ taken $20.27 \pm 1.90 \mathrm{sec}$ to paralysis the earthworm and $20.52 \pm 1.94$ sec for Death.

- Test group three with Dose $15 \mathrm{mg} / \mathrm{ml}$ taken $20.12 \pm 1.84 \mathrm{sec}$ to paralysis the earthworm and $20.36 \pm 1.89 \mathrm{sec}$ for Death.

- Test group four with Dose $20 \mathrm{mg} / \mathrm{ml}$ taken $19.50 \pm 1.89 \mathrm{sec}$ to paralysis the earthworm and $20.12 \pm 1.85 \mathrm{sec}$ for Death.

- Test group five with Dose $25 \mathrm{mg} / \mathrm{ml}$ taken $19.22 \pm 1.75 \mathrm{sec}$ to paralysis the earthworm and $19.43 \pm 1.79 \mathrm{sec}$ for Death.

- Standard group (Albendazole) with Dose $25 \mathrm{mg} / \mathrm{ml}$ taken $33 \pm 2.05 \mathrm{~min}$ to paralysis the earthworm and $35 \pm 2.08 \mathrm{~min}$ for Death.

Table 1: Showing phenyl etherneolamarckia cadamba fruit extract effects in earthworm in different doses

\begin{tabular}{|c|c|c|c|c|}
\hline Group no. & Group name & Dose (mg/ml) & Time take for Paralysis (min) & Time take for death (min) \\
\hline 1 & Test group (PENCFE) & 5 & $20.34 \pm 1.95$ & $21 \pm 1.99$ \\
\hline 2 & Test group (PENCFE) & 10 & $20.27 \pm 1.90$ & $20.52 \pm 1.94$ \\
\hline 3 & Test group (PENCFE) & 15 & $20.12 \pm 1.84$ & $20.36 \pm 1.89$ \\
\hline 4 & Test group (PENCFE) & 20 & $19.50 \pm 1.89$ & $20.12 \pm 1.85$ \\
\hline 5 & Test group (PENCFE) & 25 & $19.22 \pm 1.75$ & $19.43 \pm 1.79$ \\
\hline 6 & Albendazole (std gp) & 25 & $33 \pm 2.05$ & $35 \pm 2.08$ \\
\hline
\end{tabular}

All values represent $=$ mean \pm SEM, $n=6$ in each group, When compared with the standard group all test groups indicates significance at $\mathrm{P}<0.05$. PENCFE-Phenyl Ether Neolamarckia Cadamba fruit extract

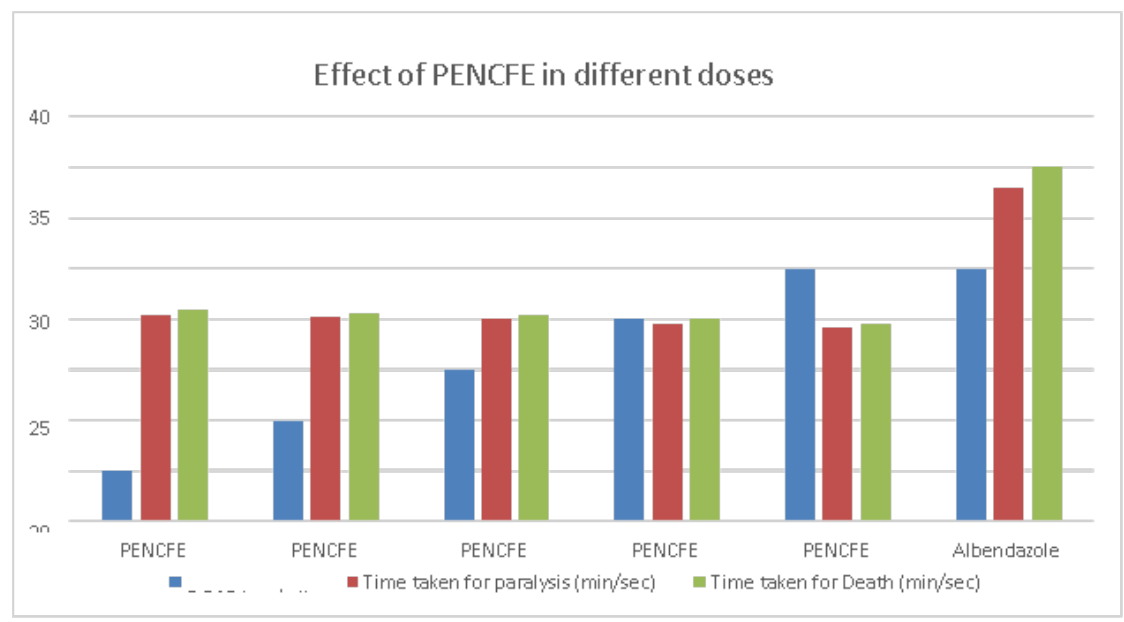

Fig. 2: Graph showing phenyl ether neolamarckia cadamba fruit extract effects in earthworm in different doses 
Evaluation of chloroform neolamarckia cadamba fruit extract effects in earthworm in different doses was shown in table 2 and fig. 3

- In Chloroform Neolamarckia Cadamba extract, test group one with Dose $5 \mathrm{mg} / \mathrm{ml}$ taken $16.14 \pm 1.70 \mathrm{sec}$ to paralysis the earthworm and $16.40 \pm 1.74 \mathrm{sec}$ for Death.

- Test group two with Dose $10 \mathrm{mg} / \mathrm{ml}$ taken $16.07 \pm 1.65 \mathrm{sec}$ to paralysis the earthworm and $16.32 \pm 1.70 \mathrm{sec}$ for Death.

- Test group three with Dose $15 \mathrm{mg} / \mathrm{ml}$ taken $15.52 \pm 1.60 \mathrm{sec}$ to paralysis the earthworm and $16.16 \pm 1.64 \mathrm{sec}$ for Death.

- Test group four with Dose $20 \mathrm{mg} / \mathrm{ml}$ taken $15.30 \pm 1.54 \mathrm{sec}$ to paralysis the earthworm and $15.52 \pm 1.59 \mathrm{sec}$ for Death.

- Test group five with Dose $25 \mathrm{mg} / \mathrm{ml}$ taken $15.02 \pm 1.50 \mathrm{sec}$ to paralysis the earthworm and $15.23 \pm 1.61 \mathrm{sec}$ for Death.

- Standard group (Albendazole) with Dose $25 \mathrm{mg} / \mathrm{ml}$ taken $32.50 \pm 2.04 \mathrm{sec}$ to paralysis the earthworm and $35 \pm 2.07 \mathrm{~min}$ for Death.
Evaluation of ethanol neolamarckia cadamba fruit extract effects in earthworm in different doses were shown in table 3 and fig. 4

- In Ethanol Neolamarckia Cadamba extract, test group one with Dose $5 \mathrm{mg} / \mathrm{ml}$ taken $9.10 \pm 1.21 \mathrm{sec}$ to paralysis the earthworm and $9.36 \pm 1.24$ sec for Death.

- Test group two with Dose $10 \mathrm{mg} / \mathrm{ml}$ taken $9.03 \pm 1.16 \mathrm{sec}$ to paralysis the earthworm and $9.28 \pm 1.20 \mathrm{sec}$ for Death.

- Test group three with Dose $15 \mathrm{mg} / \mathrm{ml}$ taken $8.48 \pm 1.11 \mathrm{sec}$ to paralysis the earthworm and $9.12 \pm 1.15 \mathrm{sec}$ for Death

- Test group four with Dose $20 \mathrm{mg} / \mathrm{ml}$ taken $8.26 \pm 1.06 \mathrm{sec}$ to paralysis the earthworm and $8.48 \pm 1.09 \mathrm{sec}$ for Death

- $\quad$ Test group five with Dose $25 \mathrm{mg} / \mathrm{ml}$ taken $7.58 \mathrm{sec}$ to paralysis the earthworm and $8.19 \mathrm{sec}$ for Death.

- Standard group (Albendazole) with Dose $25 \mathrm{mg} / \mathrm{ml}$ taken $31.50 \pm 2.00 \mathrm{sec}$ to paralysis the earthworm and $34 \pm 2.03 \mathrm{~min}$ for Death.

Table 2: Showing chloroform neolamarckia cadamba fruit extract effects in earthworm in different doses

\begin{tabular}{|c|c|c|c|c|}
\hline Group no. & Group name & Dose (mg/ml) & Time take for paralysis (min) & Time take for death (min) \\
\hline 1 & Test group (CHNCFE) & 5 & $16.14 \pm 1.70$ & $16.40 \pm 1.74$ \\
\hline 2 & Test group (CHNCFE) & 10 & $16.07 \pm 1.65$ & $16.32 \pm 1.70$ \\
\hline 3 & Test group (CHNCFE) & 15 & $15.52 \pm 1.60$ & $16.16 \pm 1.64$ \\
\hline 4 & Test group (CHNCFE) & 20 & $15.30 \pm 1.54$ & $15.52 \pm 1.59$ \\
\hline 5 & Test group (CHNCFE) & 25 & $15.02 \pm 1.50$ & $.15 .23 \pm 1.61$ \\
\hline 6 & Albendazole (std gp) & 25 & $32.50 \pm 2.04$ & $35 \pm 2.07$ \\
\hline
\end{tabular}

All values represent $=$ mean \pm SEM, $n=6$ in each group, When compared with the standard group all test groups indicates significance at $\mathrm{P}<0.05$. CHNCFE-Chloroform Neolamarckia Cadamba fruit extract.

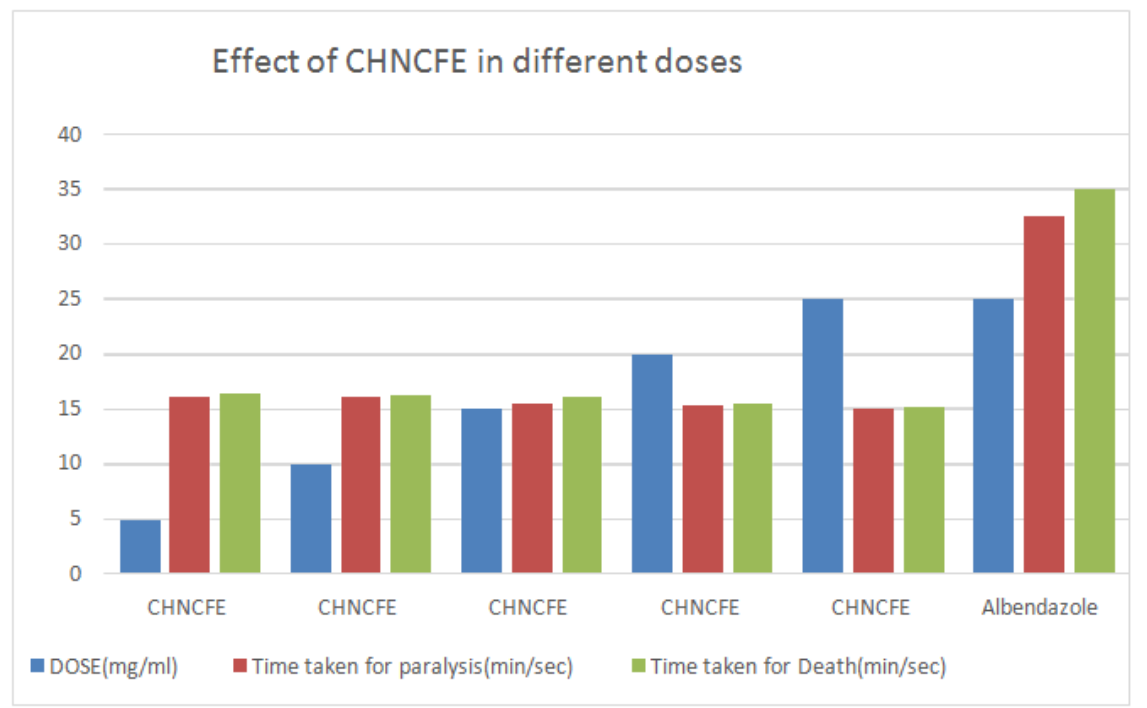

Fig. 3: Graphshowing chloroform neolomarckia cadamba fruit extract effects in earthworm in different doses

Table 3: Showing ethanol neolamarckia cadamba fruit extract effects in earthworm in different doses

\begin{tabular}{|c|c|c|c|c|}
\hline Group no. & Group name & Dose (mg/ml) & Time take for paralysis (min) & Time take for death (min) \\
\hline 1 & Test group (ENCFE) & 5 & $9.10 \pm 1.21$ & $9.36 \pm 1.24$ \\
\hline 2 & Test group (ENCFE) & 10 & $9.03 \pm 1.16$ & $9.28 \pm 1.20$ \\
\hline 3 & Test group (ENCFE) & 15 & $8.48 \pm 1.11$ & $9.12 \pm 1.15$ \\
\hline 4 & Test group (ENCFE) & 20 & $8.26 \pm 1.06$ & $8.48 \pm 1.09$ \\
\hline 5 & Test group (ENCFE) & 25 & $7.58 \pm 1.01$ & $8.19 \pm 1.05$ \\
\hline 6 & Albendazole (std gp) & 25 & $31.50 \pm 2.00$ & $34 \pm 2.03$ \\
\hline
\end{tabular}

All values represent $=$ mean $\pm S E M, n=6$ in each group, when compared with the standard group all test groups indicates significance at $\mathrm{P}<0.05$. ENCFE:-Ethanol Neolamarckia Cadamba fruit extract 


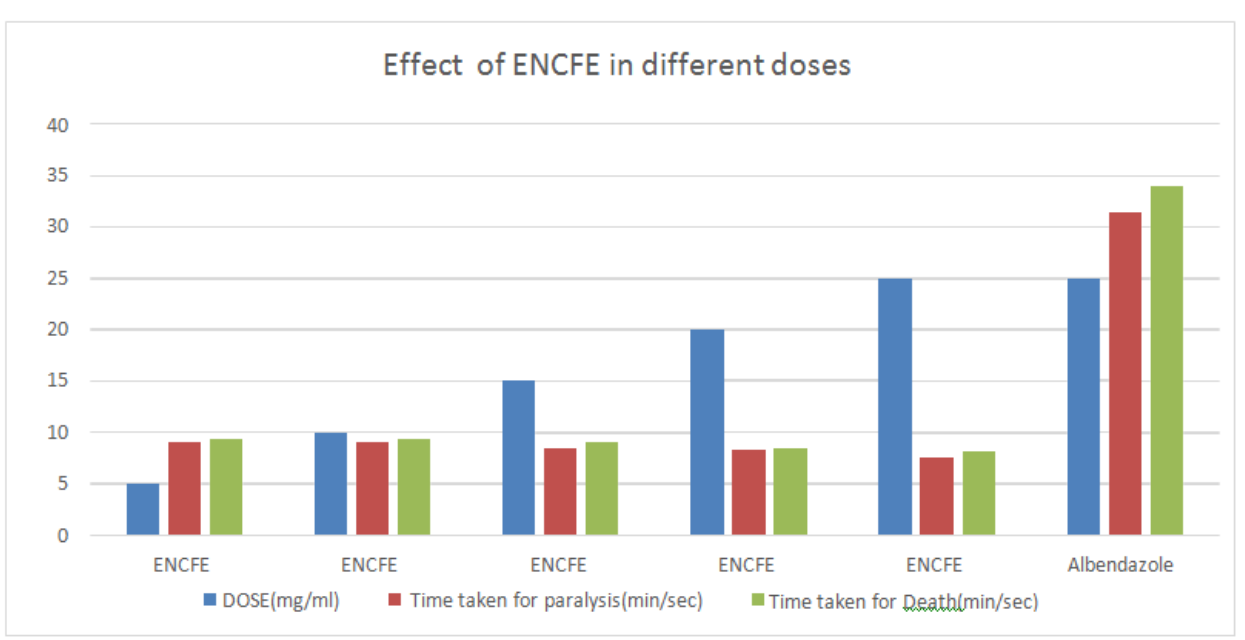

Fig. 4: Graph showing ethanol neolamarckia cadamba fruit extract effects in earthworm in different doses

Table 4: Phytochemical screening of different extracts of A. cadambafruit

\begin{tabular}{llllll}
\hline Extracts & Alkaloids & Carbohydrates gums & Gums and mucilages & Saponins & + \\
\hline Petroleum Ether & - & - & - & - & + \\
Chloroform & + & - & - & + \\
Ethanol & + & - & - & + \\
Aqueous & - & - & - & - \\
\hline
\end{tabular}

Table 5: Phytochemical screening of different extracts of A. cadambafruit

\begin{tabular}{lllll}
\hline Extracts & Proteins and amino acids & Tannins and phenolic compounds & Triterpenoids & Flavonoids \\
\hline Petroleum Ether & - & - & + & + \\
Chloroform & - & - & - & + \\
Ethanol & + & + & - & + \\
Aqueous & + & + & + & + \\
\hline
\end{tabular}

\section{DISCUSSION}

Ascaris lumbricoides is a parasitic worm that infects about 2 billion people globally. Malaria is common in developing nations. Parasitic diseases are more prevalent among children and in regions with poor sanitation. The sickness of our patient was most likely caused by a shortage of safe drinking water. Ascariasis is caused by ingesting embryonated eggs. Embryonic larvae migrate to the mucosa of the colon and hatch there. They then go via the liver and lungs, over the alveolar space, and into the pharynx. They are reswallowed and returned to the gut to sexually develop. Ascariasis is influenced by lifestyle, socioeconomics, and unsanitary faeces practises. However, 8-15 percent of infected people have gastrointestinal, respiratory, or neurological symptoms. A large population of roundworms in the stomach may sometimes cause life-threatening complications. The purpose of this research was to see whether the fruit extract of Neolamarckia cadamba is efficient in killing the worms that cause ascaris. The resulting sata is assisting in the management of the disease. Anthelmintics are medications that are used to treat parasitic worm infections. Flukes, tapeworms, nematodes, and flat worms are all included. They play an important role in both human and veterinary tropical medicine. The WHO believes that 2 billion people are infected with parasitic worms. Parasitic worms cause harm to animals and crops, decreasing food production and harming the economy. Infection of domestic pets is also a major concern. Indeed, the companion animal business is a major economic issue for pharmaceutical companies. Despite the prevalence of parasitic worms, anthelmintic medication research remains a laggard in the pharmaceutical industry. The majority of the world's tropical disease sufferers have little money to spend on drug research or therapy. As a result, it's no surprise that the majority of human medicines began as veterinary treatments. It is important because it has the highest concentration of phytochemicals and secondary metabolites. India, Bangladesh, Nepal, Myanmar, Sri Lanka, Cambodia, Laos, the Philippines, Malaysia, Indonesia, Papua New Guinea, and Australia are all home to this species. It is a kind of ayurvedic diabetes therapy. It also aids in the treatment of a number of infections. Kadamba is very beneficial to diabetics. It is used to treat prostate, colon, breast, and esophageal cancers. Antifungal properties of kadamba the most active extract is ethanolic extract. In comparison to other extracts and conventional medicines, it shows paralytic effect sooner and dies faster (Albendazole). Alkaloid, saponin, tannins, flavonoids, proteins, and amino acids were all present. Finally, in anthelmintic activity against Indian earthworms, ethenolic fruit extract of Neolamarckia Cadamba surpassed albendazole.

\section{CONCLUSION}

The solvents Ethanol, Chloroform, Phenyl Ether, and Aqueous were used to extract the Neolamarckia Cadamba. The results showed that Ethanolic extract has the greatest degree of activity. When compared to any other extract or conventional medicine, it produces a paralytic effect sooner and has a shorter time to death (Albendazole). An ethanol extract included alkaloid, saponin, tannins, flavonoids, proteins, and amino acids. As a result, it is possible to infer that the ethenolic fruit extract of Neolamarckia Cadamba has much more anthelmintic activity against Indian earthworms than the conventional treatment (Albendazole).

\section{ACKNOWLEDGMENT}

It's our privilege to express profound sense of gratitude and cordial thanks to our respected chairman Mr. Anil Chopra, Vice Chairperson Ms. Sangeeta Chopra and Pro-Chairman Mr. Prince Chopra, St. Soldier Educational Society, Jalandhar for providing the necessary facilities to complete this research work. 


\section{FUNDING}

\section{Nil}

\section{AUTHORS CONTRIBUTIONS}

All the authors have contributed equally.

\section{CONFLICTS OF INTERESTS}

There are no conflicts of interest

\section{REFERENCES}

1. Haque Rashidul. Human intestinal parasites. J Health Popul Nutr. 2007;25(4):387-91.

2. Fahim SM, Das S, Gazi MA, Mahfuz M, Ahmed T. Association of intestinal pathogens with faecal markers of environmental enteric dysfunction among slum-dwelling children in the first 2 years of life in Bangladesh. Trop Med Int Health. 2018 Nov;23(11):1242-50. doi: 10.1111/tmi.13141, PMID 30133067.

3. Weatherhead JE, Hotez PJ. Worm infections in children. Pediatr Rev. 2015 Aug;36(8):341-52; quiz 353-4. doi: 10.1542/pir.368-341, PMID 26232464

4. https://www.cdc.gov/parasites/ascariasis/index.html. [Last accessed on 01 Apr 2021]

5. Darlington CD, Anitha GFS. Ascaridial volvulus: an uncommon cause of ileal perforation. Iran J Med Sci. 2018;43(4):432-5. PMID 30046214.
6. Zakzuk J, Casadiego S, Mercado A, Alvis-Guzman N, Caraballo L. Ascaris lumbricoides infection induces both, reduction and increase of asthma symptoms in a rural community. Acta Trop. 2018 Nov;187:1-4. doi: 10.1016/j.actatropica.2018.07.016, PMID 30040946

7. https://www.healthline.com/health/ascariasis\#roundwormlifecycle. [Last accessed on $01 \mathrm{Apr}$ 2021]

8. Saurabh Sethi MD. MPH Written by health editorial team; 2019.

9. Dept of Medicine, Henry J. Carter specialty hospital and nursing facility, New York: USA; 1965.

10. https://web.stanford.edu/group/parasites/ParaSites2005/Asc aris/JLora_ParaSite.htm [Last accessed on 01 Apr 2021]

11. Prasad S, Bhattacharya IC. Chemical study of the bark of Anthocephalus indicus Rich. Ind J Pharmacol. 1960;22:172-4.

12. Shilpi M, Ashish M, Padmini S, Prabodh S. In vitro anthelmintic activity of enicostemma littorale blume Int. J. Pharm. Sci. Res. 2011;2(5):1193-6.

13. Thorn GW, Adams RD, Braunwald E, Isselbacher KJ, Petersdrof RG. Harrison's principles of internal medicine. New York: Mcgraw-Hill Co.; 1977. p. 1088-9.

14. Vigar Z. Atlas of medical parasitology. 2nd ed. Singapore: Procter \& Gamble Publishing House; 1984. p. 216-7.

15. The wealth of India. A dictionary of Indian raw materials and industrial products. New Delhi, India: NISCAIR press publishers; 1962. p. 305-8.

16. Patel D, Kumar V. pharmacognostical studies of neolamarckia cadamba (roxb.) Bosser leaf. Int J. Green Pharm. 2008;2(1):26 7. doi: 10.4103/0973-8258.39159 